\title{
Parler sans suffoquer
}

\author{
Louise Cotnoir
}

\section{To Speak Without Suffocating}

Since writing is a form of consciousness, what happens when a woman's consciousness constructs a narrative? Women writers question our culture's power to symbolize experience by bringing new propositions from their own until-now unexpressed existence. The structure of their stories is articulated through conflict, tension and paradox. A story based on conflict, such as Nicole Brossard's These Our Mothers, is one of protest against the contingency of women's lives, their erasure; it oscillates between theory and fiction, affirmation and anecdote. Other stories based on tension interrogate the injustice and injury done to women in a poetic expression of women's suffering, like France Theoret's We Will Speak as They Write. Thirdly, there are novels built on paradox, like Gail Scott's Heroine, which play with men's utterances, twisting them until they expose women's deprivation as well as the 'scandal' of the primacy of the female subject.

Construire une narration c' est, au sens large, raconter une histoire, une série d'événements faisant sens. Le récit interroge tout à la fois le fonctionnement énonciatif et la praxis sociale. Or, qu'en est-il lorsqu' une conscience-femme travaille à produire ce type de discours? Qu'arrive-t-il lorsqu'elle cherche à traduire son rapport au monde dans une forme, si possible, neuve? Quel récit donne-t-elle à lire, quelle portion jusqu'alors ignorée de l'existence, sa part aveugle, metelle en jeu?

Si nous analysons les récits produits par cette conscience-femme, nous constatons qu'au niveau de la trame (de l' histoire racontée) que leur univers romanesque s'articule soit sur le conflit, la tension ou le paradoxe. Et bien évidemment, la trame du récit va conditionner l'écriture, l'expression qui en seront les véhicules. Dans chacune de ces narrations, les auteures questionnent le pouvoir de symboliser 
l'expérience humaine par la juxtaposition de différents espaces émotionnels et tentent de créer un 'ego expérimental' capable d'apporter une connaissance nouvelle à l'ensemble de l'expérience humaine.

\section{Le récit de conflit}

Le récit basé sur le conflit exprime souvent la colère devant ce qui empêche un être de sexe féminin d'atteindreà la vie. L'histoire, dans ce cas, se formule comme une protestation contre la représentation démentielle du monde dans lequel les femmes se tiennent constamment menacées. Le récit parle de la vie contingente des femmes, deson annulation, d'un destin raturé. Le récit qui s'écrit est celui du scandale, c'est-à-dire de l'indignation et de la révolte devant le sort extravagant fait aux femmes. L'écriture qui en résulte est celle de la protestation,

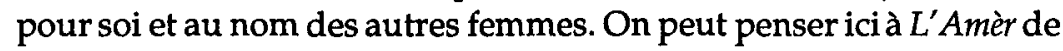
Nicole Brossard où le texte oscille entre théorie et fiction, entre énoncés affirmatifs et propos anecdotiques. Ces oeuvres ont le sérieux avantage de montrer, de démontrer qu'il peut y avoir coïncidence entre les représentations de soi que peut avoir un être féminin et le sens que ce même être peut avoir dans le réel, quele privé est politique. On accuse souvent les auteures de ces récits $\mathrm{d}^{\prime}$ inféoder leur imaginaire à une idéologie comme si tout discours, quellequesoit la forme qu'il prenne, n'était pas un véhicule idéologique...

\section{Le récit de tension}

D'autres narrations écrites avec une conscience-femme ont pour fondement la tension; elles s'attaquent à la soumission féminine traditionnelle sans pouvoir imaginer quelques formes de libération. Le choix des événements que ces récits racontent est fait en fonction de donner à entendre des vérités insupportables, de faire parler l'inimaginable. Ils questionnent l'injure et l'injustice faites auxêtres féminins. Je pense ici à l'extraordinaire roman de France Théoret, Nous parlerons comme on écrit. Une telle problématique tient le récit au bord de la folie (fureur autodestructrice) qui est l'une des alternatives traditionnellement féminines ou, au bord du suicide qui est une façon d'exprimer le refus de la protagoniste à vivre dans une structure narrativeculturelle qui la confine à la non-existence, statut qui est envisagé comme pire que la mort elle-même. Le texte s'écrit avec les mots pris dans la gorge ou bien, les mots s'échappent à travers les sanglots et les cris. Il $s^{\prime}$ apparente en ce sens à la poésie qui est l'expression par excellence de 
la souffrance. Le texte dénonce l'hostilité dont les femmes sont victimes, les mensonges du langage qui font prendre la mort pour de la vie, qui font croire aux femmes que la fusion, l'absence de différence sont des équivalents del'amour; alors quel'organisation (matérielleet symbolique) du discours reconduit la protagoniste à l'inexistence, au vide et à la mort en tant que sujète.

\section{Le récit de paradoxe}

Il y a enfin les récits qui reposent sur le paradoxe. Ce sont des textes où s'enchevêtrent l'affirmation et le rejet du féminin. Basés sur la contradiction, ils mettent en jeu les énoncés des hommes, les plagient jusqu'à ce qu'apparaisse la spoliation des êtres-femmes par le discours, jusqu'à ce qu'ils dénoncent les images dont elles sont accablées. Avec humour, je qualifie ces auteures 'd'agents doubles'. Elles travestissent et détournent (parfois avec beaucoup d'ironie) le langage pour faire apparaître le 'scandale scandaleux': la primauté du sujet-féminin. Je pense ici au roman Héroïne de Gail Scott qui, dans les deux langues (!), en créant un pont entre cause et effet, donne aux êtres féminins accès au monde, trouve les raisons qui militent en faveur de leur révolte et en énonce la spécificité. Un tel récit déroge aux 'modèles prestigieux', affirme la 'liberté de penser autrement' et inscrit cette oeuvre dans la culture au sens anthropologique du terme, $c^{\prime}$ est-à-dire que ce roman questionne les institutions politiques et sociales, les structures familiales, les croyances, les technologies d'un point de vue strictement féminin.

L'écriture de ce roman, toute en fragments, en digressions, en paradoxes nous renvoie à des images de 'femmes aveuglées' qui participent à l'ordre patriarcal tout autant qu'à des images d'Amazones, $\mathrm{d}^{\prime}$ Hérö̈nes au sens de 'personnage principal d'une oeuvre littéraire' mais aussi, de 'femmes douées d'un courage hors de commun, de vertus exceptionnelles'. Héroine est une sorte de kaléidoscope de l'univers féminin ou mieux, un hologramme de ce qu' est 'le féminin' dans un réel halluciné et hallucinant.

Ce qu'il faut retenir de cette trop brève analyse, c'est que puisque l'écriture reste un mode de connaissance, il faut bien admettre que toutes ces écrivaines (chacune à sa façon) font de nouvelles propositions à notre culture et à notre société. 